\title{
Reshaping Apple Juice Production Into a Zero Discharge Biorefinery Process
}

\author{
Josipa Lisičar Vukušić ${ }^{1}$. Thomas Millenautzki ${ }^{1}$. Ronny Cieplik ${ }^{2}$. Veit Obst ${ }^{3} \cdot$ Abdechafik Mokhlis Saaid $^{1}$. \\ Leonardo Clavijo $^{4}$. Slododan Zlatanovic ${ }^{2}$. Jendrik Hof ${ }^{5} \cdot$ Marek Mösche $^{5} \cdot$ Stéphan Barbe ${ }^{1}$ (D)
}

Received: 7 November 2018 / Accepted: 14 September 2020 / Published online: 19 September 2020

(C) The Author(s) 2020

\begin{abstract}
In the last decade, the utilization of waste by-product apple pomace has been extensively researched (due to its difficult disposal) and currently finds beneficial usage in various industries; as substrate for microbial growth or recovery of pectin, xyloglucan and polyphenols. In this research apple juice was produced at pilot scale. Furthermore, apple pomace was employed as substrate for the production of pectin, biofuel (pellets) and concentrated apple pomace extract. Extensive mass and heat balances were conducted to evaluate the feasibility of this approach on industrial scale. The produced pellets had very similar characteristics to wood pellets (net calorific value of $20.3 \mathrm{MJ} / \mathrm{kg}$ ). Dried apple pomace contained $11.9 \%$ of pectin. Fed-batch cultivation of baker's yeast with apple pomace extract demonstrated a potential for partial substitution of molasses in industrial bioprocesses. This concept shows how a zero discharge biorefinery process converts waste from apple juice production into three valuable products enabling connections between different industries.
\end{abstract}

Stéphan Barbe

stephan.barbe@th-koeln.de

1 Faculty of Applied Natural Sciences, Technische Hochschule Köln, Kaiser-Wilhelm-Allee, 51373 Leverkusen, Germany

2 Faculty of Information Science and Communication Studies, Technische Hochschule Köln, Steinmüllerallee 1, 51643 Gummersbach, Germany

3 Faculty of Mathematics and Natural Sciences, Bergische Universität Wuppertal, Gausstr. 20, 42119 Wuppertal, Germany

4 Faculty of Engineering, Universidad de La República, Av. J. Herrera y Reissig 565, 11300 Montevideo, Uruguay

5 Uniferm GmbH \& Co. KG, Industriestraße 2, 40789 Monheim am Rhein, Germany 


\section{Graphic Abstract}

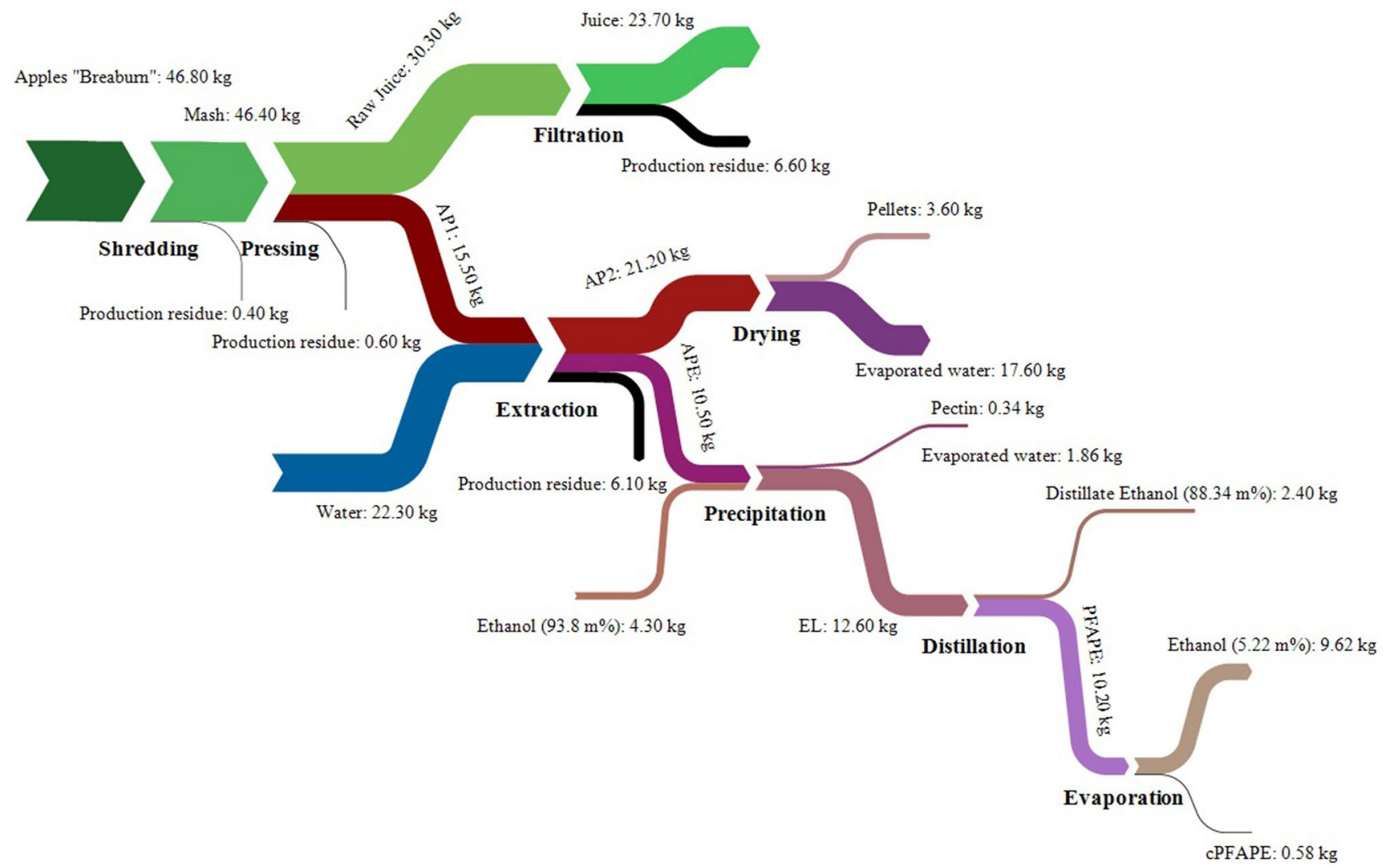

Keywords Apple juice $\cdot$ Apple pomace $\cdot$ Pectin $\cdot$ Pellets $\cdot$ Saccharomyces cerevisiae

\section{Statement of Novelty}

Apple pomace could be a fully valorised product. A zero discharge biorefinery concept is presented; it generates value added products (Pectin, Feed Stock \& Biofuels) out of this stream.

\section{Introduction}

Apple is one of the most favoured and consumed fruits by mankind widely grown in temperate regions of the world [1, 2]. Its yearly production in 2016 was 89.33 million tonnes [3]. Most of the fruit is used fresh and around $13 \%$ in apple juice manufacture [4]. In 2017739 thousand tonnes of apple juice was produced in Germany (Fig. 1).

In large scale apple juice production, the raw juice represents $75 \%$ of the processed apple mass and the remaining $25 \%$ is the by-product, apple pomace [1]. The processing of apples begins with washing and sorting (removal of damaged and diseased fruit). Apples are then grinded by a disintegrator, hammer mill or grating mill. In order to achieve higher yields of juice (break down cell walls), lower the viscosity and reduce pulp slipperiness, commercial macerating enzymes are usually added. The extraction is accomplished through pressing chopped apple continuously (by belt or screw press) or in batches (by hydraulic or bladder press). The produced apple juice is extremely cloudy and contains particles that can be removed by screening. In this case a cylindrical "cider" screen can be used which revolves on a system of rollers. The screen is kept clean by revolving actions causing the pomace to gather into small balls and finally into a continuous roll which falls off the end of the slightly sloping screen. For the "natural" look associated with fresh apple juice, the ground apple pulp is treated with ascorbic acid before pressing to minimize browning. The juice is screened or settled, but not otherwise filtered. Ascorbic acid is added directly to the mill, to be mixed with the pulp after the apples are crushed and pulp exposed to air. If the final product is meant to be cloudy, then the enzyme step is not applied. Otherwise, after juice extraction, the raw apple juice is treated with enzymes to remove suspended solids, which would consequently clog filters, slow the 
Fig. 1 Production of apple juice in Germany in the years 2004 to 2017 (in millions of L) [5]

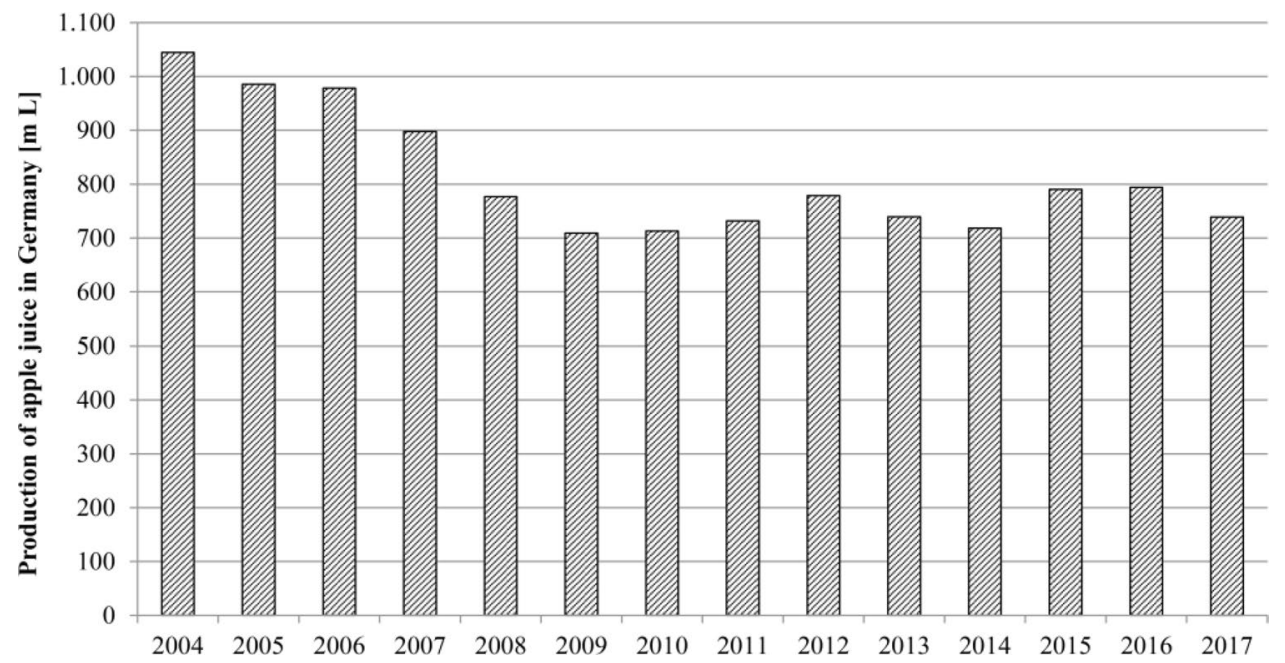

production and may cause the juice to form a haze. These enzymes hydrolyse pectin, hemicellulose and other polymers and colloids that increase viscosity of the juice. Enzyme treatment can either be performed as hot method (at $54{ }^{\circ} \mathrm{C}$ for one to two hours) or cold method (at room temperature, $20{ }^{\circ} \mathrm{C}$ for six to eight hours). Further processing involves heat clarification, fining, filtration and pasteurisation. Basic idea of heat clarification is that heated particles within the apple juice coagulate and are easily removed through filtration. In the fining process, bentonite clay particles absorb tannins and protein-tannin complexes. By filtration large particles, certain proteins and microorganisms are being removed from the apple juice. The final and the most important step for preserving the juice is pasteurisation, which involves heating to a given temperature long enough to destroy all organisms that can develop. Flash pasteurization is rapid heating to near the boiling point (above $88^{\circ} \mathrm{C}$ ) for 25 to $30 \mathrm{~s}$, in which steam or hot water passes the juice between plates or through narrow tubes that are heated [6].

Considering the large volumes of apple juice being produced, by-product apple pomace is generated worldwide in thousands of tonnes (Table 1). The production of apple pomace in Germany is particularly high (250,000 t/year).

Apple pomace is generally composed of skin and flesh (95\%), seeds ( $2 \%$ to $4 \%$ ), and stems (1\%). Its composition has been widely explored (Table 2 ) and differ depending on the variety, origin and processing technology prior to its generation [2].

The disposal of apple pomace into the environment, due to its high bio-chemical oxygen demand, represents a pollution problem. Direct dumping is also difficult, because of the high costs of transportation and the generation of foul smell. In the past, dried apple pomace was used as animal feed, fuel for boilers or added to soil as a conditioner. In the last 30 years its potential has been extensively studied as a
Table 1 Apple pomace generation in some countries worldwide [7]

\begin{tabular}{ll}
\hline Country & $\begin{array}{l}\text { Quantity } \\
\text { (thousands of } \\
\text { tonnes) }\end{array}$ \\
\hline Brazil & 13.75 \\
Germany & 250 \\
India & $3-5$ \\
Iran & 97 \\
Japan & 160 \\
New Zealand & 20 \\
Spain & 20 \\
United States & 27 \\
\hline
\end{tabular}

substrate for microbial growth and used in the production of value products such as organic acids, enzymes, single cell proteins, low alcoholic drinks, ethanol, biogas, pigment and baker's yeast [13]. Since fresh apple pomace is quite liable to spoil, it must be preserved in order to be stored and used over a long period of time. Preservation can be achieved by drying. Dried apple pomace has demonstrated its worth on animal health and can be utilized for animal feed [14, 15]. It has also been characterized by high pellet-ability [16].

One of the most practical approaches in the utilization of apple pomace is for pectin production [7]. Pectin is a structural linear polysaccharide contained in the primary cell walls of terrestrial plants [17]. Commercial pectin is characterised by high content of galacturonic acid, which has become part of the definition for pectin to be used as food additive or for pharmaceutical purposes. Usual requirements are a minimum of $65 \%$ of galacturonic acid on the ash and moisture-free substances [18]. Excellent water binding and gel forming properties even at low concentrations is the main reason to be employed as thickener and stabiliser in the food industry as gelling agent in jams, 
Table 2 Examples of physicalchemical composition of apple pomace (expressed in \% of dry weight basis) (TDF total dietary fibre, $n . d$. not determined)

\begin{tabular}{lllllll}
\hline Composition (\%) & \multicolumn{7}{l}{ References } & & & & \\
\cline { 2 - 7 } & {$[8]$} & {$[9]$} & {$[10]$} & {$[11]$} & {$[12]$} & {$[13]$} \\
\hline Moisture & $3.97-5.4$ & 3.0 & $3.9-10.8$ & 11.43 & 7.9 & 9.0 \\
Ash & 1.6 & n. d & $0.5-6.1$ & 1.8 & 1.1 & 1.6 \\
Fat & $3.49-3.9$ & 1.5 & $1.2-3.90$ & 1.53 & 2.3 & 2.27 \\
Protein & $4.45-5.67$ & n. d & $2.94-5.67$ & 2.74 & 3.3 & 2.37 \\
Carbohydrate & $48.0-62.0$ & n. d & $48.0-62.0$ & n. d & n. d & 84.76 \\
Starch & n. d & n. d & n. d & n. d & 7.8 & 5.6 \\
Total sugar & n. d & n. d & n. d & n. d & n. d & 54.2 \\
Glucose & 22.7 & 6.7 & $19.5-19.7$ & 12.57 & n. d & n. d \\
Fructose & 23.6 & 19.9 & 40.3 & 17.93 & n. d & n. d \\
Saccharose & 1.8 & 11.8 & $3.8-5.8$ & 7.04 & n. d & n. d \\
TDF & $4.7-48.72$ & 55.2 & $4.7-51.1$ & 43.63 & 42.1 & 30.15 \\
Pectin & $3.5-14.32$ & n. d & $3.5-14.32$ & 15.27 & n. d & 7.84 \\
\hline
\end{tabular}

confectionary and bakery fillings, as well as stabilizer in yoghurts and milk drinks. It is also used in the cosmetics, personal care (paints, toothpaste and shampoos) and pharmaceutical industry (gel caps), including new utilization as nutraceutical ingredient. Since the early 2000s, pectin has been recognized to have several beneficial health and nutritional effects as a dietary fibre and prebiotic. Conventional pectin production is generally expensive, requiring extraction factories having a close, large-scale source of raw material (dried citrus peel or apple pomace). In 2015 the average price exceeded $15 \$ / \mathrm{kg}$ and the market (exceeding 60,000 tons) was close to reach $\$ 1$ billion [19].

The aim of this research was to produce apple juice and to discharge by-product apple pomace by converting it from waste to high value products. In this regard, apple pomace was further processed and generated three products: pectin, pellets and a pectin free apple pomace extract (PFAPE). Pellets of dry apple pomace were examined in order to be employed as a biofuel. Mass and heat balance were discussed. The performance of PFAPE as a molasses supplement in industrial fed-batch fermentation of baker's yeast Saccharomyces cerevisiae was evaluated. The results were used to present a concept for an industrial biorefinery and energy savings. The presented process should be regarded as an approach to turn apple juice production into a zero-discharge process by creating interfaces with new industries.

\section{Materials and Methods}

\section{Production of Apple Juice}

$46.8 \mathrm{~kg}$ of Braeburn apples (New Zewaland Apple LTD, Whakatu, New Zealand) were washed and grinded by Shark Fruit 1.6 kW (Vares Mnichovice a.s.; Mnichovice, Czech
Republic). Crushed apples were pressed at the pressure of 3 bar (Speidel Hydropresse 20 L; Ofterdingen, Germany) resulting in $30.3 \mathrm{~kg}$ of raw juice (RJ) and $15.5 \mathrm{~kg}$ of apple pomace 1 (AP1). Raw apple juice was filtrated (Sheet filter $20 \times 20$ FZ 20, Zambelli; Vicenza, Italy; Depth filters Seitz K 100, Pall Filterysystems GmbH; Bad Kreuznach, Germany) and pasteurized at $73^{\circ} \mathrm{C}$ for ten minutes (Eltac EKA 179; Viersen, Germany) and filled in Bag-in-Box containers (Fig. 2).

\section{Extraction of Pectin and Sugar}

Prior to the extraction, the $\mathrm{pH}$ value of demineralized water was adjusted to 1 by $37 \%$ hydrochloric acid (Carl Roth; Karlsruhe, Germany). The extraction was performed by mixing $22.25 \mathrm{~kg}$ of water with $15.5 \mathrm{~kg}$ of AP1 (ratio 1.44) and boiled at $90{ }^{\circ} \mathrm{C}$ for one hour while constantly being stirred. The mixture was cooled down to $40{ }^{\circ} \mathrm{C}$ and then pressed (Vares Hydraulic Profi 18L/2t, Vares Mnichovice a.s.; Mnichovice, Czech Republic). The solid fraction-so called apple pomace 2 (AP2) — was used to produce pellets (P) and the liquid fraction-so called apple pomace extract (APE) was collected. $10.5 \mathrm{~kg}$ of APE was mixed with $4.3 \mathrm{~kg}$ of $93.8 \%$ (w/w) ethanol (Merck; Darmstadt, Germany) and cooled down to $4{ }^{\circ} \mathrm{C}$ overnight. The following day, it was pressed by hydraulic press. The gained solid pectin (PT) was dried at $40{ }^{\circ} \mathrm{C}$ for seven days (Shel Lab; Oregan, USA) and the ethanolic liquor (EL) was subjected to distillation in order to produce a pectin free apple pomace extract (PFAPE).

\section{Distillation and Production of PFAPE}

Batch distillation was performed by a rectification apparatus DN50 (Normag Labor- und Prozesstechnik GmbH; 
Fig. 2 Production of apple juice, pectin and pectin free apple pomace extract (AP1 apple pomace $1, A P 2$ apple pomace $2, R J$ raw juice, $P$ pellets, $A P E$ apple pomace extract, $P T$ solid pectin, $d P T$ dried pectin, $E L$ ethanolic liquor, $P F A P E$ pectin free apple pomace extract, $C P F A P E$ concentrated pectin free apple pomace extract)

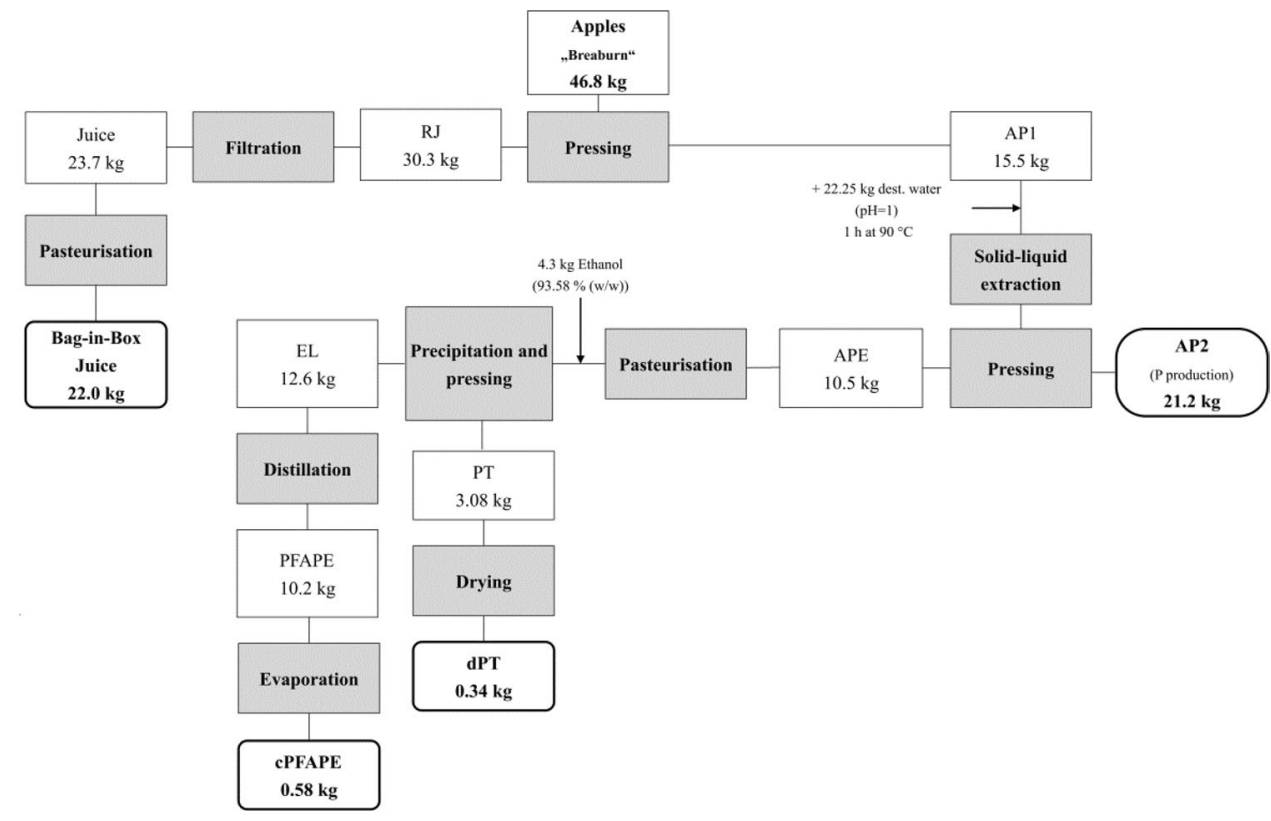

Ilmenau, Germany). The column, filled with Raschig-rings, had a diameter of $50 \mathrm{~mm}$ and a filling height of $1200 \mathrm{~mm}$, whereby 7 theoretical plates are realized. The capacity of the boiling flask is $10 \mathrm{~L}$ and is operated with electric heating device (maximum heat output $1.6 \mathrm{~kW}$ ). For the separation of EL, a heating power of $0.72 \mathrm{~kW}$ was set. At the beginning of the batch distillation, the unit was retracted at reflux ratio 0.2 with a starting head temperature of $76.5^{\circ} \mathrm{C}$. After $165 \mathrm{~min}$, $6.47 \mathrm{~kg}$ of apple pomace extract was obtained and $2.37 \mathrm{~kg}$ ethanol with purity of $88.34 \%$ (w/w) were recovered. PFAPE was concentrated to obtain $0.58 \mathrm{~kg}$ concentrated pectin free apple pomace extract (cPFAPE) by evaporation in a scraped surface evaporator (Normag Labor- und Prozesstechnik $\mathrm{GmbH}$; Ilmenau, Germany) for six hours and $30 \mathrm{~min}$ at a temperature of $80{ }^{\circ} \mathrm{C}$, pressure of $130 \mathrm{mbar}$ and rotation speed of $150 \mathrm{rpm}$.

\section{Production and Analysis of Pellets}

$21.2 \mathrm{~kg}$ of AP2 were dried at $60{ }^{\circ} \mathrm{C}$ for $24 \mathrm{~h}$ (Heraeus Instruments TK 6060; Hanau, Germany) and then used as raw material for pellet production (EcoWorxx Pelletmaker PM22E, EcoWorxx GmbH; Raddestorf, Germany). Moisture content of $\mathrm{P}$ was determined at $105{ }^{\circ} \mathrm{C}$ until constant weight. Durability was determined according to the standard ISO 17831-1:2015(en) (Solid biofuels-Determination of mechanical durability of pellets and briquettes-Part 1: Pellets") [20] (Pelletsabriebtester Bioenergy Tumbler 1000, Bioenergy Anlagenplanung GmbH; Vienna, Austria). Net calorific value was determined according to ISO 18125:2017(en) (Solid biofuels-Determination of calorific value) [21] (IKA Calorimeter C200, IKA GmbH \& Co.; Staufen, Germany).

\section{Determination of Dry Matter}

The solid content was determined by using drying oven (Shel Lab; Oregon, USA). Three to five grams of sample was heated for $24 \mathrm{~h}$ at the temperature of $105^{\circ} \mathrm{C}$.

\section{Determination of Ash Content}

A muffle furnace (Nabertherm S27 Controller L3; Lilienthal Germany) was used for the determination of ash content. The dried samples were heated for two hours at the temperature of $550{ }^{\circ} \mathrm{C}$.

\section{Determination of Sugar Concentrations}

The concentrations of sucrose, glucose, and fructose have been determined enzymatic with the commercial kit (EnzytecTM D-Glucose/D-Fructose/Sucrose, R-Biopharm AG; Darmstadt, Germany) as well as by refractometer (0-32\%, Greiner Glasinstrumente GmbH; Lemgo, Germany).

\section{Fed-Batch Fermentation of Baker's Yeast}

Large-scale yeast inoculum Saccharomyces cerevisiae was kindly provided by Uniferm $\mathrm{GmbH} \& \mathrm{Co}$; Monheim am Rhein, Germany. 
Two fermentations were conducted; one with the molasses and the second one with the mixture of molasses and cPFAPE as carbon source. All the other steps and course of the fermentation were the same for both cultivations. The $15 \mathrm{~L}$ bioreactor (Infors, Techfors-S; Bottmingen, Switzerland) was filled with $5 \mathrm{~L}$ of sterile tap water and $30 \mathrm{~g}$ of monoammonium phosphate (VWR International; Radnor, Pennsylvania, USA). The molasses medium, a sterile mixture of sugar beet and cane molasses, was kindly provided by Uniferm $\mathrm{GmbH} \& \mathrm{Co}$, Monheim am Rhein, Germany. The medium for the cultivation contained $93 \%$ of the molasses and $7 \%$ of cPFAPE. Prior to mixing, cPFAPE was first centrifuged (Sorvall RC-5B Plus Superspeed Centrifuge; Thermo Fisher Scientific; Waltham, Massachusetts, USA) and neutralized with a $2.5 \mathrm{M}$ sodium hydroxide solution (Carl Roth; Karlsruhe, Germany). Brix value of 73 was lowered to 44 with the addition of demineralized water. The noticeable solid particles were removed via filtration (Filter paper MN 540 we, $\varnothing 150 \mathrm{~mm}$; Düren, Germany) and the medium was sterilised (Eltac EKA 179; Viersen, Germany). $4 \mathrm{~kg}$ of substrate (molasses or molasses-cPFAPE mixture) were supplemented with a vitamin stock solution. The bioreactor was inoculated with $180 \mathrm{~g}$ of yeast (concentration of $0.737 \mathrm{~g} / \mathrm{g}$ ). The fed-batch cultivation was performed at the temperature range from 30 to $36{ }^{\circ} \mathrm{C}$ and the $\mathrm{pH}$-range from 4 to 6.2 (kept at specific value by $25 \%$ sulfuric acid (Merck; Darmstadt, Germany)) with molasses/cPFAPE and $10 \%$ ammonium solution (Carl Roth; Karlsruhe, Germany) as substrates. The dissolved-oxygen concentration was kept above $10 \%$ of air saturation at an impeller speed of $800 \mathrm{rpm}$ at the beginning followed by $1150 \mathrm{rpm}$. The samples were centrifuged (Minizentrifuge IKA® mini G, IKA Werke GmbH \& Co. KG, Staufen im Breisgau, Germany) for $10 \mathrm{~min}$ at $6,000 \mathrm{rpm}$, washed twice with $0.9 \% \mathrm{NaCl}$ (Merck; Darmstadt, Germany) for the determination of dry yeast biomass and fermentative capacity. The concentration of dry yeast biomass was determined via vacuum furnace (Nabertherm S27 Controller L3; Lilienthal Germany) at $105{ }^{\circ} \mathrm{C}$ for $24 \mathrm{~h}$. Fermentative capacity, the increase of the ethanol concentration (Ethanol UV Method, R-Biopharm; Darmstadt, Germany) was determined in two different synthetic doughs (low sugar synthetic dough (LSSD) and high sugar synthetic dough (HSSD)) [22].

\section{Process Simulation}

The simulation of continuous distillation was conducted by means of software ChemSep (ChemSep Lite v7.3) (Table 3). Figures were made by softwares e!Sankey 4 and Microsoft Visio 2010.
Table 3 Input parameters for continuous distillation in ChemSep Lite v7.3

\begin{tabular}{ll}
\hline Type of simulation & Equilibrium column \\
\hline Operation & \\
Configuration & \\
Operation & Simple distillation \\
Condenser & Total (liquid product) \\
Reboiler & Partial (liquid product) \\
Number of stages & 15 \\
Feed stages & 12 \\
Properties & \\
Thermodynamics & \\
K-value & \\
Equation of state & DECHEMA \\
Activity coefficient & Ideal gas law \\
Vapour pressure & UNIFAC \\
Enthalpy & Antoine \\
Enthalpy/exergy & Excess \\
Reference state & \\
Heat of formation & Vapour 298,15 K \\
Surroundings T & Excluded \\
Heat Capacity IG & $298,15 \mathrm{~K}$ \\
Heat Capacity L & T correlation \\
Reflux ratio & Mol fraction average \\
Mass fraction water $(/)$ & 1.50 \\
Feed & \\
Top & 0.727521 \\
Bottom & 0.0930107 \\
\hline & 0.990247 \\
\hline
\end{tabular}

\section{Results and Discussion}

\section{Mass and Heat Balance in the Production of Apple Juice, Pectin, Pellets and Pectin Free Apple Pomace Extract}

Mass balance of apple processing into apple juice and further into pectin, pellets and pectin free apple pomace extract are presented in Fig. 3. It is important to mention that unlike in industrial production, pectin-degrading enzyme was not used during the production of apple juice in this research.

After shredding and pressing, $30.3 \mathrm{~kg}$ of raw apple juice was obtained, meaning $65 \%$ of apples was utilized for juice production, which correspond the literature [23]. The losses that remained in the equipment during the production as well as for sampling were taken into consideration. Bag-in-box apple juice contained total sugar concentration of $102.7 \mathrm{~g} / \mathrm{L}$, which is in good agreement with the literature [24]. The extraction of AP1 is a critical step from an economic point of view. Namely, the more water added, the more energy is required during the drying process, more ethanol is need for the precipitation and more energy is required for the 


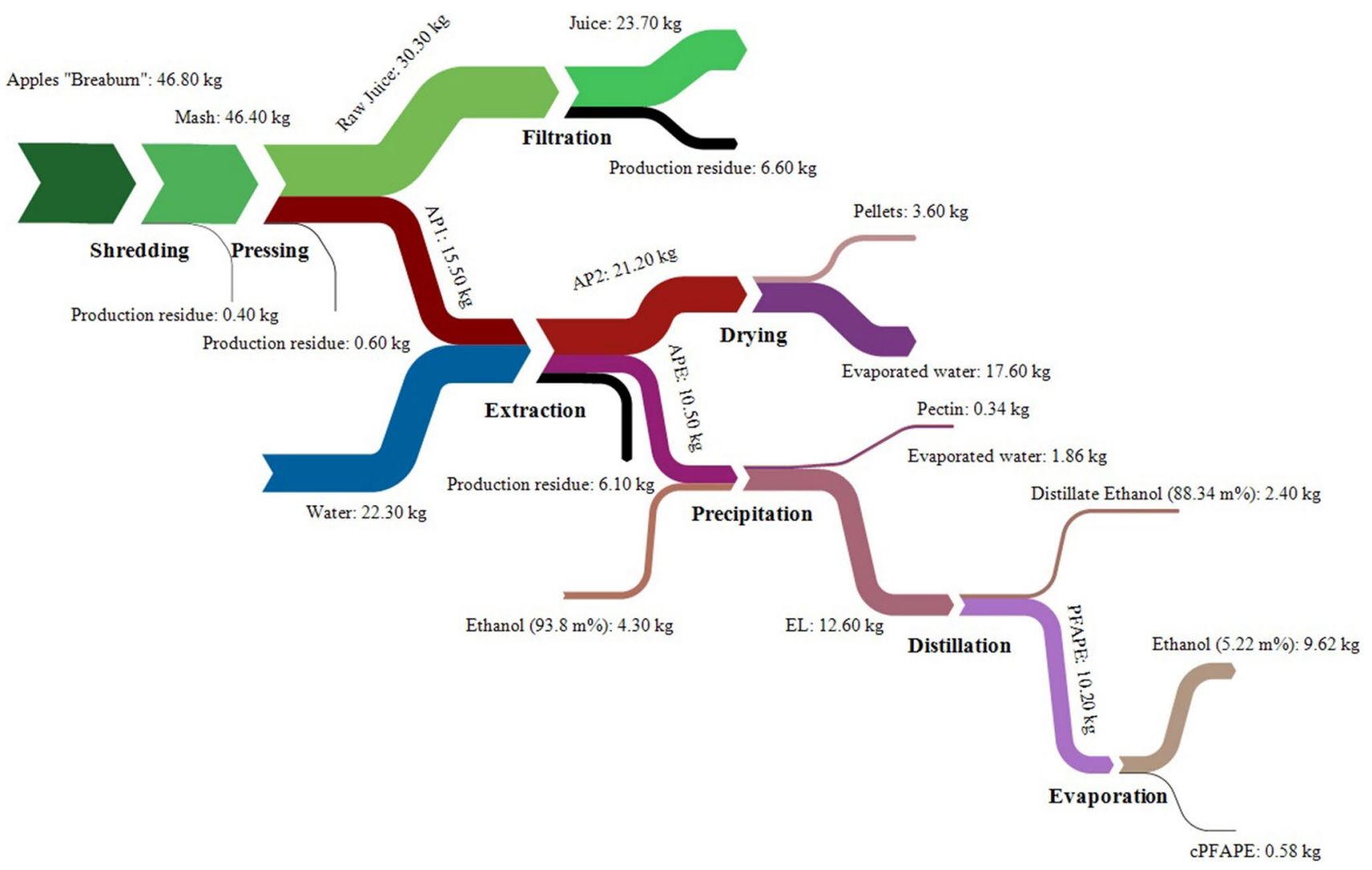

Fig. 3 Mass balance of apple processing into apple juice, pectin, pellets and pectin free apple pomace extract

distillation and concentration processes. In this research, the extraction was conducted with a water/AP1 ratio 1.44 which resulted in $21.2 \mathrm{~kg}$ of AP2 and $10.5 \mathrm{~kg}$ of APE. Dried AP2 was employed as substrate for pelleting. Apple pellets, with the moisture content of $17.1 \%$, were further analysed. Pellet durability index amounted $96.9 \%$, which is slightly lower than found in literature [16]. However, measured net calorific value of $20.312 \mathrm{MJ} / \mathrm{kg}$ is higher than found in literature [25] and very similar to the value obtained with wood pellets [26]. Precipitation of extract with ethanol resulted in $3.08 \mathrm{~kg}$ of soluble pectin, i.e. in $0.34 \mathrm{~kg}$ of dried pectin. To be exact, AP contained $11.89 \%$ of pectin on dry matter (which corresponds to literature in Table 2). Batch distillation proved to be a successful step in recovering ethanol and obtaining PFAPE (Fig. 4). The head temperature was kept at ethanol's boiling point $\left(78.3{ }^{\circ} \mathrm{C}\right)$. Starting bottom temperature was $82{ }^{\circ} \mathrm{C}$ and by having less and less ethanol in the fraction and more water content, the temperature tended to rise. The reflux ratio could be kept below 1 for $108 \mathrm{~min}$. Then it required to be higher and was kept at 7 for $37 \mathrm{~min}$. The distillation was stopped as the head temperature suddenly increased because of the presence of water in the distillate. By distillation $2.4 \mathrm{~kg}$ of $88.34 \%$ (w/w) ethanol was recovered and $10.2 \mathrm{~kg}$ PFAPE obtained as bottom product.
APE still contained ethanol $(5.22 \%(\mathrm{w} / \mathrm{w}))$ and water which were removed by evaporation. Obtained final product cPFAPE amounted $0.58 \mathrm{~kg}$ with Brix value of 73 .

Energy demands for drying of AP2, drying of pectin, distillation and evaporation were calculated (Fig. 5). As mentioned the extraction is a critical step. Water was mixed with AP1 in ratio 1.44. It resulted in $21.2 \mathrm{~kg}$ of AP2, which required energy of $2.892 \mathrm{MJ} / \mathrm{kg}_{\mathrm{AP} 1}$ for the drying process to evaporate $17.6 \mathrm{~kg}$ of water, considering an evaporation enthalpy of $2546.5 \mathrm{~kJ} / \mathrm{kg}$ [27]. This step consumes the most energy. To gain dPT the energy demand was $0.306 \mathrm{MJ} /$ $\mathrm{kg}_{\mathrm{AP1}}$. Batch distillation process consumed $1.833 \mathrm{MJ} / \mathrm{kg}_{\mathrm{AP1}}$, based on the evaporation enthalpy of ethanol $839 \mathrm{~kJ} / \mathrm{kg}$ [27]. $1.621 \mathrm{MJ} / \mathrm{kg}_{\mathrm{AP} 1}$ was required in the evaporation process to gain cPFAPE. Calculated total energy obtained from the pellets combustion is as high as $3.938 \mathrm{MJ} / \mathrm{kg}_{\mathrm{AP} 1}$. However, the usual energy efficiency of boilers is approximately $90 \%$ [28], meaning the pellets are generating $3.544 \mathrm{MJ} / \mathrm{kg}_{\mathrm{AP} 1}$ energy. Combusting the pellets does not cover all energy demands required for the drying of AP2, distillation, evaporation and drying of pectin; an additional input of $3.108 \mathrm{MJ} / \mathrm{kg}_{\mathrm{AP} 1}$ is required. It might be more useful to use the pellets for more lucrative purposes such as feed (about $300 \$ /$ ton) or anaerobic digestion. 
Fig. 4 Relation of temperatures and reflux ratio during the batch distillation
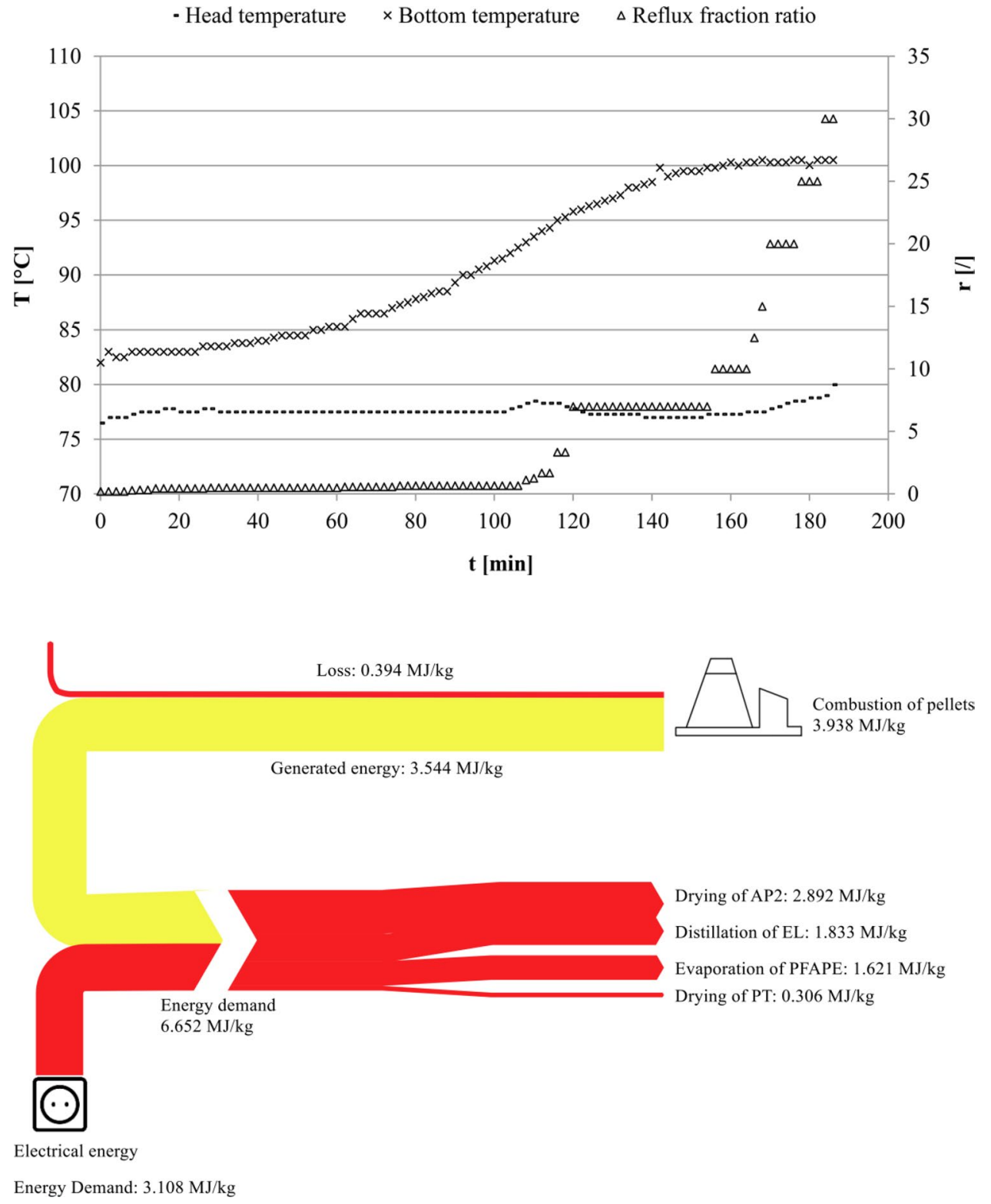

Fig. 5 Heat balance in the production of pectin, pellets and pectin free apple pomace extract in $\mathrm{MJ} / \mathrm{kg}_{\mathrm{AP} 1}$

\section{Fed-Batch Cultivation}

cPFAPE was tested in fed-batch fermentation of baker's yeast in order to explore its potential as an alternative to overpriced molasses [29]. The results are presented in Table 4. Concentration of dry yeast biomass obtained on the medium consisted of molasses and cPFAPE is slightly lower than the yield obtained on the medium containing only molasses. However, baker's yeast end concentration is still higher than found in literature [23]. It has been reported, and was also proved in this research, that baker's yeast shows lower fermentative capacity in HSSD-medium, due to the overexpression of invertase and intrinsic osmotolerance triggered by high sugar environment [22]. Slightly lower production of ethanol in HSSD is achieved by the yeast grown
Table 4 Maximum biomass yield (on dry matter in $\mathrm{g}$ ) and fermentative capacity in two synthetic doughs (in $\mathrm{mmol}_{\text {Ethanol }} / \mathrm{g} / \mathrm{h}$ ) of Saccharomyces cerevisiae produced on molasses and molasses and CPFAPE

\begin{tabular}{llll}
\hline Medium & $\begin{array}{l}\text { Dry yeast biomass } \\
(\mathrm{g})\end{array}$ & $\begin{array}{l}\text { Fermentative capacity } \\
\left(\mathrm{mmol}_{\text {Ethanol }} \mathrm{g} / \mathrm{h}\right)\end{array}$ \\
\cline { 2 - 4 } & & HSSD & LSSD \\
\hline $\begin{array}{l}\text { Molasses } \\
\begin{array}{l}\text { Molasses and } \\
\text { cPFAPE }\end{array}\end{array}$ & 630 & 1.806 & 4.014 \\
\hline
\end{tabular}

on the medium containing cPFAPE. However, the higher fermentative capacity is achieved in LSSD medium by the yeast produced on cPFAPE. These results indicate that cPFAPE 
can be used as an alternative substrate for the production of baker's yeast. cPFAPE 's Brix value was 73, which is significantly higher than the value in diluted molasses used in baker's yeast production but nearly the same as the Brix value of pure molasses [30]. Considering the high prices of molasses, if only a portion of molasses is replaced with cPFAPE (for example 10\%), it would significantly reduce the costs of producing baker's yeast. If baker's yeast manufacture requires 100.000 tonnes of molasses/year, with the substitution of $10 \%$, the cost reduction would amount $\$ 1$ million. Additionally cPFAPE is being converted from the waste by-product into valuable source of nutrients which contributes to integrated sustainability in the industrial environment, where the waste from one industrial process is used as feedstock for another [31].

\section{Industrial Concept of Biorefinery}

In this study, apple juice was successfully produced at pilot scale. Also by-product apple pomace was processed so that three valuable products were obtained. However, to process large amounts of apple pomace, modifications have to be implemented. As previously mentioned, the most critical step in this work flow is the extraction process, considering that water needs to be removed in latter phases which require large amounts of energy. Batch distillation is not profitable on industrial scale. That is why the simulation of continuous distillation was performed and four scenarios were developed (Table 5). Different water/AP1 ratios for extraction process were investigated (1.08 and 0.72 ) as well as the same one used in the experimental part of batch distillation (1.44), in order to reduce the energy input into the overall process. We assumed that the water content in AP2 was constant for water/AP1 ratios $>0.4$.

The energy demand is reduced for every step, except for AP2 and pectin drying and combustion of pellets, which remained the same. When applying water/AP1 ratio of 1.44 in extraction process, the energy demand input for overall process, in which continuous distillation is applied,

Table 5 Theoretical scenarios of energy requirements and demand by applying different water/AP1 ratio for extraction process

\begin{tabular}{llll}
\hline Ratio water/AP1 for extraction process & 1.44 & 1.08 & 0.72 \\
\hline Energy requirements (MJ/kg $\mathrm{AP1}_{\mathrm{A} 1}$ ) & & & \\
$\quad$ Drying of apple pomace 2 & 2.892 & 2.892 & 2.892 \\
Continuous distillation & 0.718 & 0.538 & 0.359 \\
Evaporation & 1.621 & 1.216 & 0.811 \\
Drying of pectin & 0.306 & 0.306 & 0.306 \\
Total & 5.536 & 4.951 & 4.366 \\
Energy generated from pellets & 3.938 & 3.938 & 3.938 \\
Energy demand & 1.598 & 1.013 & 0.428 \\
\hline
\end{tabular}

is almost $60 \%$ reduced than in process in which batch distillation is used (reduction of $1.598 \mathrm{MJ} / \mathrm{kg}_{\mathrm{AP1}}$ ). Simulation showed that if $7.068 \mathrm{~kg}$ of water is mixed with $15.5 \mathrm{~kg}$ of AP1 (ratio 0.455) in the extraction process, the energy demand for overall process would be entirely covered by the combustion of pellets (Fig. 6).

The developed biorefinery concept is shown in Fig. 7. Besides the equipment for the industrial production of apple juice, the distillation apparatus and equipment for producing pectin are integrated in the plant. By producing and combusting pellets, the energy demand can be covered in this chain, with the emphasis of carefully designing the extraction process. cPFAPE partly substitutes raw material molasses in the production of baker's yeast. This concept does not only include the valorisation of the entire waste steam but also generates energy.

Considering the results obtained in this study and amount of apple juice produced in Germany in 2017 (Table 1), the corresponding amount of apple pomace produced is approx. 398,000 tonnes, i.e. 73,400 tonnes on dry matter. The amount of pectin that could be recovered equals 8,730 tonnes, which corresponds to almost $15 \%$ of global production accomplished in year 2015 and has worth of more than $\$ 130$ million. Amount of pellets that could be produced equals 92,400 tonnes, which by combusting generate energy of over 1.4 million GJ. The amount of concentrated pectin free pomace extract produced would be over 15,000 tonnes.

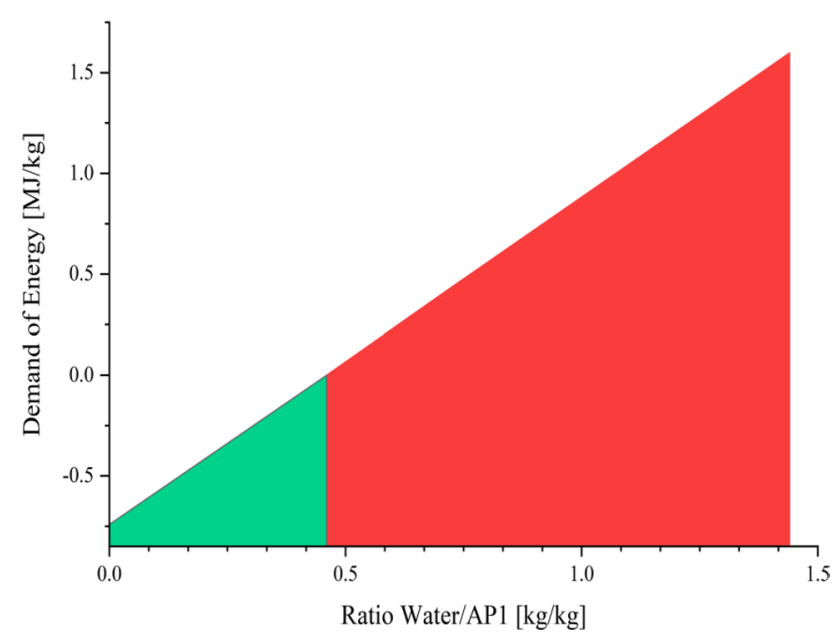

Fig. 6 Energy input (in $\mathrm{MJ} / \mathrm{kg}_{\mathrm{AP} 1}$ ) required for the process in correlation with ratio water/AP1 


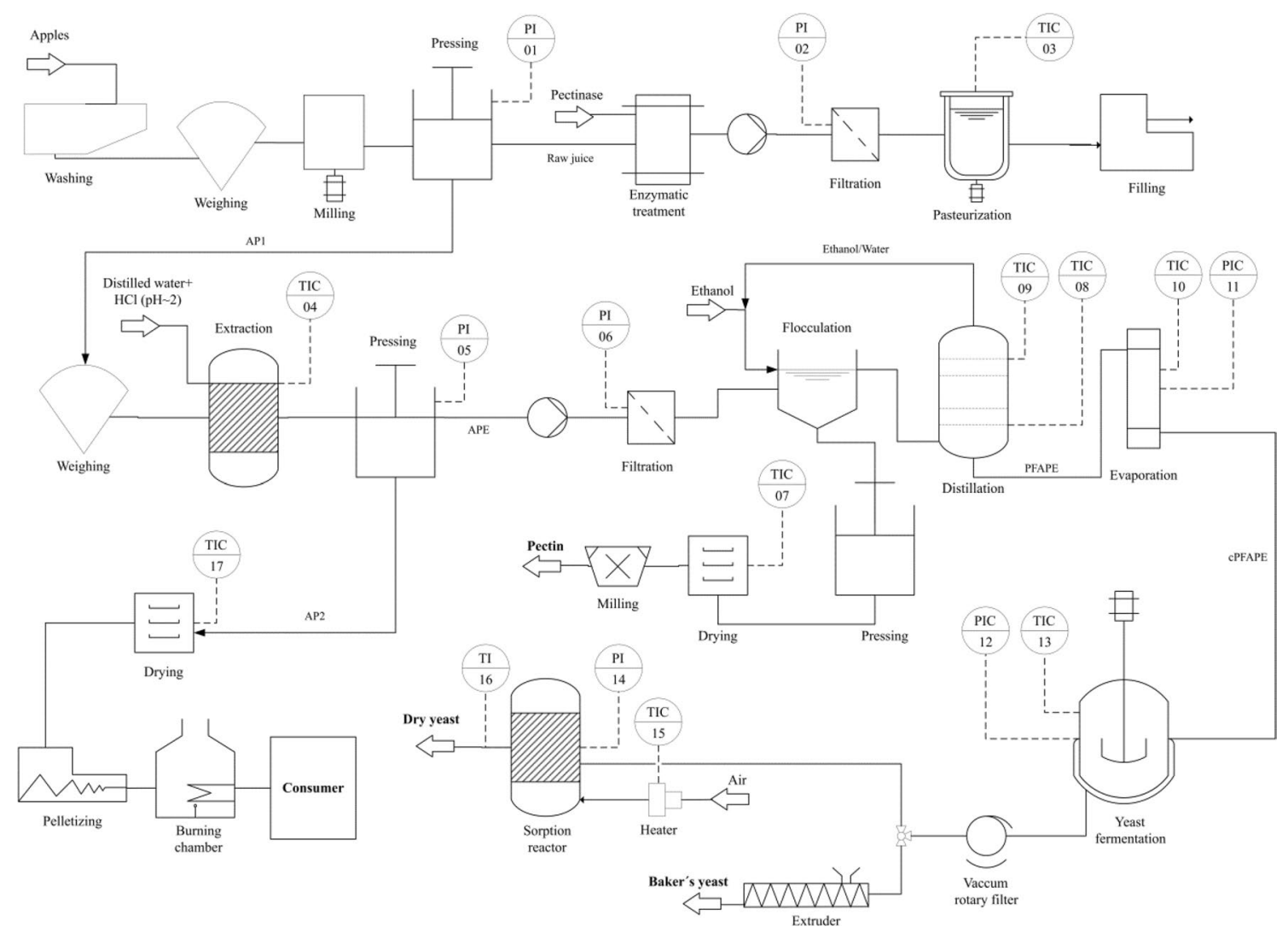

Fig. 7 Apple juice production turned into biorefinery platform

\section{Conclusions}

This study demonstrated how by-product of apple juice production can be fully valorised, resulting in pectin, pellets and pectin free apple pomace extract. The process of apple juice production was similar to the industrial process, only commercial enzyme of any kind and ascorbic acid have not been used. The critical step of extraction has been discussed as well as the possible scenarios of industrial continuous distillation, considering batch process was applied in recovering ethanol. $3.6 \mathrm{~kg}$ of pellets were produced in this work and the net calorific value of $20.3 \mathrm{MJ} / \mathrm{kg}$ is practically the same as the one reported for wood pellets. Apple pomace proved to contain $11.9 \%$ of pectin. Concentrated pectin free apple pomace extract showed potential to be employed as a carbon source for the growth of baker's yeast. Slightly lower biomass yield is obtained in the medium containing CPFAPE and molasses than in the medium containing only molasses. However, yeast produced on alternative substrate possessed a bit higher fermentative activity than the one produced on molasses. By reshaping this production, a biorefinery platform in which waste from one production stream is used as feedstock in another industrial process, could be set up. It would provide not only value-added products but would also generate energy for its own use. Scaling up calculations showed that almost $15 \%$ of global pectin production could be covered by this biorefinery, 15,000 tonnes of alternative raw medium for baker's yeast production could be produced and 92,420.8 tonnes of pellets would generate approx. 20.2 GJ per tonne of pellets. One of the problems for setting up a biorefinery concept is the raw material availability. However, apple pomace is widely available and eligible for multiple purposes. Further investigations regarding extraction and distillation process are necessary in order to turn this production into zero discharge biorefinery process.

Funding Open Access funding enabled and organized by Projekt DEAL.

\section{Compliance with Ethical Standards}

Conflict of interest The authors declare that they have no conflict of interest.

Open Access This article is licensed under a Creative Commons Attribution 4.0 International License, which permits use, sharing, adaptation, distribution and reproduction in any medium or format, as long as you give appropriate credit to the original author(s) and the source, 
provide a link to the Creative Commons licence, and indicate if changes were made. The images or other third party material in this article are included in the article's Creative Commons licence, unless indicated otherwise in a credit line to the material. If material is not included in the article's Creative Commons licence and your intended use is not permitted by statutory regulation or exceeds the permitted use, you will need to obtain permission directly from the copyright holder. To view a copy of this licence, visit http://creativecommons.org/licenses/by/4.0/.

\section{References}

1. Shalini, R., Gupta, D.K.: Utilization of pomace from apple processing industries: a review. J. Food Sci. Technol. (2010). https:// doi.org/10.1007/s13197-010-0061-x

2. Perussello, C.A., Zhang, Z., Marzocchella, A., Tiwari, B.K.: Valorization of apple pomace by extraction of valuable compounds. Compr. Rev. Food Sci. Food. Saf. (2017). https://doi. org/10.1111/1541-4337.12290

3. FAO: Global fruit production in 2016 , by variety (in million metric tonnes). Statista. https://www.statista.com/statistics/264001/ worldwide-production-of-fruit-by-variety/ (2018). Accessed 17 July 2018

4. U.S. Apple Production: Production Utilization Analysis Apples. U.S. Apple Association. https://usapple.org/wp-content/uploa ds/2016/09/2016ProductionUtilization Analysis.pdf (2016) Accessed 17 July 2018

5. Statistisches Bundesamt: Production volume of apple juice in Germany in the years 2004 to 2017 (in millions of L). Statista. https://de.statista.com/statistik/daten/studie/76869/umfrage/fruch tsaftindustrie-produktionsmenge-von-apfelsaft-seit-2004/ (2018). Accessed 17 July 2018

6. Bates, R. P., Morris, J. R., Crandall, P. G.: Principles and practices of small- and medium-scale fruit juice processing. Food \& Agriculture Organization of the United Nations (FAO), Rome (2001)

7. Bhushan, S., Kalia, K., Sharma, M., Singh, B., Ahuja, P.S.: Processing of apple pomace for bioactive molecules. Crit. Rev. Biotechnol. (2008). https://doi.org/10.1080/07388550802368895

8. Joshi, V.K., Attri, D.: Solid state fermentation of apple pomace for the production of value added products. Nat. Prod. Radiance. 5(4), 289-296 (2006)

9. Kołodziejczyk, K., Markowski, J., Kosmala, M., Król, B., Płocharski, W.: Apple pomace as a source of nutraceuticals. Pol. J. Food Nutr. Sci. 57(4), 291-295 (2007)

10. Sato, M.F., Vieira, R.G., Zardo, D.M., Falcão, L.D., Nogueira, A., Wosiacki, G.: Apple pomace from eleven cultivars: an approach to identify sources of bioactive compounds. Acta Sci. Agron. (2010). https://doi.org/10.4025/actasciagron.v32i1.3176

11. Reis, S.F., Rai, D.K., Abu-Ghannam, N.: Apple pomace as a potential ingredient for the development of new functional foods. Int. J. Food Sci. Technol. (2012). https://doi.org/10.1111/ ijfs. 12477

12. O'Shea, N., Ktenioudaki, A., Smyth, T.P., McLoughlin, P., Doran, L., Auty, M.A.E., Arendt, E., Gallagher, E.: Physicochemical assessment of two fruit by-products as functional ingredients: apple and orange pomace. J. Food. Eng. (2015). https://doi. org/10.1016/j.jfoodeng.2014.12.014

13. Lisičar, J., Scheper, T., Barbe, S.: Industrial baker's yeast fermentation: From manufacture to integrated sustainability. J. Biotechnol. (2017). https://doi.org/10.1016/j.jbiotec.2017.06.630

14. Bae, D.H., Sin, C.N., Ko, K.H.: Effect of total mixed ration including apple pomace for lactating cows. Korean J. Dairy Sci. 16, 295-302 (1994)
15. Gutzwiller, A., Czeglédi, L., Stoll, P., Bruckner, L.: Effects of Fusarium toxins on growth, humoral immune response and internal organs in weaner pigs, and the efficacy of apple po-mace as an antidote. J. Anim. Physiol. Anim. Nutr. 91, 432-438 (2007)

16. Maslovarić, M., Vukmirović, Đ.M., Čolović, R., Spasevski, N.J., Jovanović, R., Tolimir, N.: Pelleting properties and pellet quality of apple pomace. Food Feed Res. (2015). https://doi.org/10.5937/ FFR1502147M

17. Srivastava, P., Malviya, R.: Sources of pectin, extraction and its applications in pharmaceutucal industry: an overviw. Indian J. Nat. Prod. Resour. 2, 10-18 (2011)

18. May, C.D.: Industrial pectins: sources, production and applications. Carbohydr. Polym. 12, 79-99 (1990)

19. Ciriminna, R., Fidalgo, A., Delisi, R., Ilharco, L.M., Pagliaro, M.: Pectin production and global market. Agro. Food Ind. Hi. Tech. 27, 17-20 (2016)

20. ISO 17831-1:2015: Solid biofuels-Determination of mechanical durability of pellets and briquettes-Part 1: Pellets, 1 st ed. ISO/ TC 238 Solid biofuels. https://www.iso.org/standard/60695.html (2015). Accessed 22 May 2018

21. ISO 18125:2017: Solid biofuels-Determination of calorific value, 1st ed. ISO/TC 238 Solid biofuels. https://www.iso.org/ standard/61517.html (2017). Accessed 22 May 2018

22. Bell, P.J.L., Higgins, V.J., Attfield, P.V.: Comparison of fermentative capacities of industrial baking and wild-type yeasts of the species Saccharomyces cerevisiae in different sugar media. Lett. Appl. Microbiol. (2001). https://doi.org/10.1046/j.1472765X.2001.00894.x

23. Bhushan, S., Joshi, V.K.: Baker'y yeast production under fed batch culture from apple pomace. J. Sci. Ind. Res. 65(1), 72-76 (2006)

24. van der Sluis, A.A., Dekker, M., Skrede, G., Jongen, W.M.F.: Activity and concentration of polyphenolic antioxidants in apple juice. 1. Effect of Existing Production Methods. J. Agric. Food Chem. (2002). https://doi.org/10.1021/jf020115h

25. Wojdalski, J., Grochowiz, J., Ekielski, A., Radecka, K., Stępniak, S., Orlowski, A., Florczak, I., Drożdż, B.: Production and properties of apple pomace pellets and their suitability for energy generation purposes. Annual Set The Environment Protection. https ://ros.edu.pl/images/roczniki/2016/005_ROS_V18_R2016.pdf (2016.) Accessed 17 Sep 2018

26. Telmo, C., Lousada, J.: Heating values of wood pellets from different species. Biomass Bioenergy (2011). https://doi.org/10.1016/j. biombioe.2011.02.043

27. VDI-Gesellschaft Verfahrenstechnik und Chemieingenieurwesen: VDI-Wärmeatlas, 11th edn., Springer, Berlin (2013)

28. Deutsches Pelletinstitut: Berechnung des Energiebedarfs von Pelletheizungen nach DIN V 4701-10: Mit Herstellerkennwerten und unter Berücksichtigung des Pufferspeichers. https://www. shk-journal.de/uploads/media/DEPI_Infoblatt_Heizenergiebeda rfsberechnung_mit_Herstellerkennwerten_150729.pdf (2015). Accessed 17 Sept 2018

29. Lisičar, J., Scheper, T., Barbe, S.: Turning industrial baker's yeast manufacture into a powerful zero discharge multipurpose bioprocess. Ind. Biotechnol. (2017). https://doi.org/10.1089/ ind. 2017.0018

30. Olbrich, H.: The Molasses. Biotechnologie-Kempe GmbH, Kelinmachnow (2006)

31. Wallace, B.: Becoming Part of the Solution: The Engineer's Guide to Sustainable Development. ACEC, Washington (2005)

Publisher's Note Springer Nature remains neutral with regard to jurisdictional claims in published maps and institutional affiliations. 